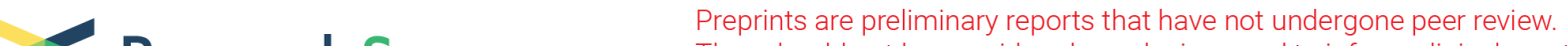 $\begin{array}{ll}\text { Research Square } & \begin{array}{l}\text { They should not be considered conclusive, used to inform clinical practice, } \\ \text { or referenced by the media as validated information. }\end{array}\end{array}$
}

\section{Measurement of Fasting Breath Hydrogen Concentration as a Simple Diagnostic Method for Pancreatic Exocrine Insufficiency}

\section{Kota Uetsuki}

Nagoya University Graduate School of Medicine Faculty of Medicine: Nagoya Daigaku Daigakuin Igakukei Kenkyuka Igakubu

Hiroki Kawashima ( $\sim$ h-kawa@med.nagoya-u.ac.jp )

Nagoya University Hospital https://orcid.org/0000-0002-3720-781X

\section{Eizaburo Ohno}

Nagoya University Graduate School of Medicine Faculty of Medicine: Nagoya Daigaku Daigakuin Igakukei Kenkyuka Igakubu

\section{Takuya Ishikawa}

Nagoya University Graduate School of Medicine Faculty of Medicine: Nagoya Daigaku Daigakuin Igakukei Kenkyuka Igakubu

\section{Tadashi lida}

Nagoya University Graduate School of Medicine Faculty of Medicine: Nagoya Daigaku Daigakuin Igakukei Kenkyuka Igakubu

\section{Kenta Yamamoto}

Nagoya University Graduate School of Medicine Faculty of Medicine: Nagoya Daigaku Daigakuin Igakukei Kenkyuka Igakubu

\section{Kazuhiro Furukawa}

Nagoya University Graduate School of Medicine Faculty of Medicine: Nagoya Daigaku Daigakuin Igakukei Kenkyuka Igakubu

\section{Masanao Nakamura}

Nagoya University Graduate School of Medicine Faculty of Medicine: Nagoya Daigaku Daigakuin Igakukei Kenkyuka Igakubu

\section{Takashi Honda}

Nagoya University Graduate School of Medicine Faculty of Medicine: Nagoya Daigaku Daigakuin Igakukei Kenkyuka Igakubu

\section{Masatoshi Ishigami}

Nagoya University Graduate School of Medicine Faculty of Medicine: Nagoya Daigaku Daigakuin Igakukei Kenkyuka Igakubu

\section{Yoshiki Hirooka}

Fujita Health University: Fujita Ika Daigaku 


\section{Mitsuhiro Fujishiro}

Nagoya University Graduate School of Medicine Faculty of Medicine: Nagoya Daigaku Daigakuin Igakukei Kenkyuka Igakubu

\section{Research article}

Keywords: pancreatic exocrine insufficiency, fasting breath hydrogen concentration, pancreatic disease, non-invasive measurement

Posted Date: February 11th, 2021

DOl: https://doi.org/10.21203/rs.3.rs-226733/v1

License: (c) (i) This work is licensed under a Creative Commons Attribution 4.0 International License.

Read Full License 


\section{Abstract}

\section{Background}

Pancreatic exocrine insufficiency (PEI) is associated with the outcome of pancreatic disease. However, there is no method for assessing PEI that can be used noninvasively and easily for outpatient. It has been reported that changes in intestinal bacteria caused by PEI may increase breath hydrogen concentration $(\mathrm{BHC})$ levels during glucose or lactose loading. We have evaluated the usefulness of fasting breath hydrogen concentration (FBHC) measurement without glucose loading for the evaluation of PEl.

\section{Methods}

Sixty patients underwent FBHC measurement, BT-PABA testing, and microbiome analysis.

They were classified into PEl group (PABA excretion rate $<73.4 \%, n=30)$ and non-PEl group $(n=30)$. The FBHC of the two groups were compared, and the diagnostic ability of PEl by them was evaluated. The 16s rRNA (V3-V4) from fecal samples was analyzed by MiSeq.

Results

FBHC levels was higher in the PEI group (15.70 (1.4 to 77.0) than in the non-PEI group 2.80 (0.7 to 28.2) ppm, $P$ 0.0001). FBHC was negatively correlated with PABA excretion rate $(r=-0.523, P<0.001)$. The cutoff value of $\mathrm{FBHC}$ of $10.7 \mathrm{ppm}(95 \% \mathrm{Cl}$ : $0.678-0.913, \mathrm{P} 0.001)$ showed a sensitivity of $73.3 \%$ and specificity of $83.3 \%$ for PEl diagnosis. In the PEI group, there was a significant increase of relative abundance of phylum Firmicutes $(P<0.05)$ and the genus Clostridium $(P<0.05)$.

Conclusion

FBHC shows good potential as a simple and repeatable test for the diagnosis of PEI. The elevated FBHC levels may be caused by hydrogen-producing bacteria such as Clostridium.

\section{Background}

Pancreatic exocrine insufficiency (PEI) is defined as 'a state of declined pancreatic enzyme activity in the intestinal lumen to a level below the threshold required to maintain normal digestion' [1]. In pancreatic disease, PEl occurs at a high frequency and causes indigestion and nutritional deficiency, which have a negative influence on nutritional status and quality of life (QOL) [2]. Pancreatic enzyme replacement therapy (PERT) significantly improves overall survival time, treatment tolerability, symptoms, and QOL of patients with pancreatic diseases such as pancreatic carcinoma (PC) and chronic pancreatitis (CP) $[3,4]$. This shows the importance of appropriate diagnosis of PEI and introduction of treatment. There are many diagnostic methods for PEl, but no consensus on the best approach in clinical practice [5]. The BTPABA test, which is the only method covered by national health insurance in Japan, is a complicated process that requires about a 6 -hour test time and fasting. 
The breath hydrogen test (BHT) for pancreatic disease was first examined in the 1960s, and this test is now mainly utilized as an indirect diagnostic method for small intestinal bacterial overgrowth syndrome (SIBO), which complicates some CP cases [6]. A study in a small number of patients suggested a relationship between PEI and SIBO [7], but the test requires measurement of breath hydrogen continuously for about $2-4$ hours in a fasting state after glucose loading $[8,9]$. Also, patients with a high fasting breath hydrogen concentration (FBHC) were excluded in many studies [10] and there is no consensus on the relationship between FBHC and pancreatic disease $[8,9]$.

We have found a significant increase in FBHC in patients with pancreatic duct stenosis, which suggests that a decline in exocrine pancreatic secretion induces changes in intestinal bacterial flora [11]. The objective of this study was to clarify the relationships among exocrine pancreatic secretion, $\mathrm{FBHC}$ and intestinal bacterial flora, and to investigate the usefulness of measuring $\mathrm{FBHC}$ as a simple diagnostic method for PEl.

\section{Methods}

Subjects

The subjects were patients aged $\geq 20$ years old in the period from April 2019 to June 2020 who agreed to participate in the study. All subjects were inpatients and were classified into those with PC, CP, other pancreatic diseases, and a normal pancreas. PC cases were histopathologically diagnosed with pancreatic duct cancer by surgery or EUS-guided fine needle aspiration. CP was diagnosed using the MANNHEIM criteria [12]. Patients admitted for a disease other than pancreatic disease and in whom pancreatic disease was excluded based on imaging and blood tests were included as subjects with a normal pancreas. The exclusion criteria were pregnancy; patients being fasted long term; use of antibiotics, probiotics, or pancreatic enzyme replacement drugs within one month before the test: history of surgery on the digestive tract or lung; presence of concomitant disease of cancer of other organs, stage 2 or advanced chronic renal failure, decompensated cirrhosis, active pulmonary disease, gastrointestinal obstruction, apparent gastrointestinal hemorrhage, caries being treated, or periodontal disease; no written consent, and judgement as inappropriate by a physician in charge $[8,9]$.

Pancreatic function test

The BT-PABA test and the 24-hour urinary $\mathrm{C}$ peptide excretion (CPR) test were performed as exocrine and endocrine pancreatic secretion tests, respectively. These tests were performed under non-fasting conditions within one week before and after measuring breath hydrogen. In both tests, the measurement was repeated 3 times on different days and the mean was used for analysis [13]. A PABA excretion rate of $<73.4 \%$ was regarded as reduced exocrine pancreatic secretion [14], and a CPR rate of $<29.2 \mu \mathrm{g} /$ day was regarded as reduced endocrine pancreatic secretion.

Breath sampling 
All patients ate a hospital meal on the day before the test and were fasted after 21:00 with drinking of water only. On the day of each breath test, the patients brushed their teeth at 7:00 a.m., breathed deeply twice, and held their breath for $15 \mathrm{~s}$ while end-expired breath was collected. Cigarette smoking, alcohol intake, excess exercise, and eating between meals were prohibited after admission. The collection method followed that of the Rome Consensus Conference and North American Consensus in 2017 [8, 9].

Expired gas analysis

A sensor gas chromatograph (SGHA, Nissha FIS Inc.) was used for measurements. Analysis of the results was performed using specialized SGC Analysis Software. Unlike general GC analysis, quantitation was performed using the peak height (= signal intensity). Hydrogen, carbon monoxide, and methane were measured and the target measurement level was 1.0-100 ppm.

Sample collection of microbiota and 16S rRNA gene sequencing

Feces collected during hospitalization were rapidly frozen. DNA was isolated from feces using a DNeasy PowerSoil Kit (Qiagen, Hilden, Germany) and amplified by targeting the V3-4 region of bacterial 16S rRNA using universal primers (forward: 5'-TCG TCG GCA GCG TCA GAT GTG TAT AAG AGA CAG CCT ACG GGN GGC WGC AG-3' and reverse: 5'-GTC TCG TGG GCT CGG AGA TGT GTA TAA GAG ACA GGA CTA CHV GGG TAT CTA ATC C-3'). The PCR products were pooled, and sequencing libraries were constructed and sequenced using an Illumina MiSeq sequencer. Pair-End Reads were prepared using MiSeq Reagent Kit v3 with $2 \times 300$ reads and 600 cycles (Illumina, San Diego, CA, USA). Analysis of 16S rRNA gene sequence data was performed using USEARCH 6.1, Microbial Ecology (QIIME 1.9.1) and Greengenes v.13_8.

Analytical methods

For between-group comparison based on the BT-PABA test, the subjects were classified into PEI and nonPEl groups based on the criterion of a PABA excretion rate of $73.4 \%$. Associations of the PABA excretion rate were examined with age, height, body mass index (BMI), pancreatic disease (PC, $C P$, and other pancreatic diseases), rates of concomitant diseases (hypertension, dyslipidemia, diabetes), history of alcohol intake, blood test findings (hemoglobin, HbA1c, creatinine, urea nitrogen, amylase, lipase, total protein, albumin, CEA, CA19-9), and presence of characteristic imaging findings in pancreatic disease (pancreatic hypertrophy, calcification, pancreatic cyst, main pancreatic duct (MPD) stenosis, and MPD dilatation). Concomitant diseases were defined as follows: hypertension, $\geq 140 / 90 \mathrm{mmHg}$ blood pressure or treatment with an oral hypotensive drug; dyslipidemia, $\geq 160 \mathrm{mg} / \mathrm{dL}$ LDL cholesterol or treatment with an LDL-lowering drug; and diabetes, $\geq 6.5 \%$ or higher hemoglobin A1c or under treatment $[15,16]$. Regarding alcohol ingestion, a subject with a history of continuous ingestion of $\geq 80 \mathrm{~g}$ pure ethanol a day [17] was defined as a heavy drinker. Pancreatic hypertrophy was defined using the criteria of Haage et al., in which the thicknesses of the pancreatic head and tail correspond to one or more vertebral bodies and $2 / 3$ or more of the vertebral body, respectively [18]. A MPD with a diameter $>3 \mathrm{~mm}$ was regarded as MPD dilatation. MPD stenosis was diagnosed using endoscopic retrograde cholangiopancreatography 
(ERCP), magnetic resonance cholangio pancreatgraphy (MRCP), and endoscopic ultrasound (EUS), and calcification and a pancreatic cyst were diagnosed using computed tomography (CT) and EUS.

The relationship between endocrine pancreatic secretion and fasting expired gas levels was investigated based on the associations of FBHC, fasting breath carbon monoxide concentration (FBCC), and fasting breath methane concentration (FBMC) with pancreatic function. For exocrine pancreatic secretion, intestinal bacterial flora were compared between the PEI and non-PEl groups.

\section{Statistical analysis}

Statistical analysis was performed using SPSS v.27.0 (IBM Corp.). All tests were 2-sided and $P<0.05$ was regarded as significant. Continuous variables were analyzed as the median and range. Comparison of data that were not normally distributed was with a non-parametric Mann-Whitney-U test. Differences in rates between two groups were examined by Fisher exact test. Correlations between expired gas levels and pancreatic function tests were analyzed using a Spearman correlation coefficient ( $r$ ). The cut-off value for FBHC for diagnosis of PEl was determined from a receiver operating characteristic (ROC) curve and the area under this curve (AUCROC), so as to maximize the Youden index (sensitivity + specificity-1). For between-group comparison of intestinal bacteria, LEfSe (http:

//huttenhower.sph.harvard.edu/galaxy/) was used with default settings.

\section{Results}

Patient background and clinical parameters

Of 80 patients who were enrolled in the study between April 2019 and June 2020, the items described above could be analyzed in 60 . The excluded patients were those for whom feces could not be acquired during hospitalization $(n=4)$, intestinal bacterial flora could not be analyzed due to the poor condition of fecal samples $(n=8)$, and antibiotic treatment was initiated before expired gas collection after admission $(n=8)$. The 60 patients were divided into PEI and non-PEI groups $(n=30$ each) based on a PABA excretion rate of $73.4 \%$ (Table 1 ). The PEl group had a significantly higher rate of heavy drinkers $(P=0.023)$, a significantly lower level of serum albumin $(P=0.006)$, and a significantly higher rate of main pancreatic duct stenosis on imaging $(P=0.038)$. In contrast, the image findings of pancreas were more frequently normal in patients in the non-PEl group $(P=0.020)$. 
Table 1

Patient background and clinical parameters

\begin{tabular}{|c|c|c|c|}
\hline & $\begin{array}{l}\text { PEl group } \\
(n=30)\end{array}$ & $\begin{array}{l}\text { non-PEl group } \\
(n=30)\end{array}$ & $P$-value \\
\hline age, median [range] & $71.0[46-87]$ & $71.0[40-81]$ & 1.000 \\
\hline gender male : female & $24: 6$ & $22: 8$ & 0.542 \\
\hline BMI, median [range] & 21.585 [15.99-28.07] & 21.090 [15.24-26.38] & 0.255 \\
\hline history of alcohol intake,n (\%) & $19(63.3)$ & $19(63.3)$ & 1.000 \\
\hline heavy drinkers, $\mathrm{n}(\%)$ & $7(23.3)$ & $1(3.3)$ & 0.023 \\
\hline smoking history,n (\%) & $17(56.7)$ & $19(63.3)$ & 0.598 \\
\hline \multicolumn{4}{|l|}{ pancreatic disease } \\
\hline PC,n (\%) & $11(36.7)$ & $12(40.0)$ & 0.791 \\
\hline CP,n (\%) & $8(26.7)$ & $3(10.0)$ & 0.095 \\
\hline other pancreatic disease,n (\%) & $11(36.7)$ & $10(33.3)$ & 0.761 \\
\hline \multicolumn{4}{|l|}{ concomitant diseases } \\
\hline hypertension,n (\%) & $10(33.3)$ & $15(50.0)$ & 0.190 \\
\hline dyslipidemia,n (\%) & $10(33.3)$ & $11(36.7)$ & 0.787 \\
\hline diabetes,n (\%) & $14(46.7)$ & $13(43.3)$ & 0.795 \\
\hline \multicolumn{4}{|l|}{ blood test findings } \\
\hline $\mathrm{Hb}(\mathrm{g} / \mathrm{dL})$ [range] & $13.50[7.9-15.5]$ & $13.50[10.9-15.9]$ & 0.877 \\
\hline BUN (mg/dL) [range] & $16.05[3.7-29.2]$ & $15.75[6.2-26.9]$ & 1.000 \\
\hline Cre (mg/dL) [range] & $0.775[0.49-1.32]$ & $0.730[0.42-1.24]$ & 0.225 \\
\hline TP (g/dL) [range] & $7.00[5.5-8.0]$ & $7.20[6.2-7.8]$ & 0.716 \\
\hline Alb (g/dL) [range] & $3.95[1.4-4.5]$ & $4.20[3.6-4.7]$ & 0.006 \\
\hline Amy (IU/L) [range] & $83.5[30-374]$ & $74.5[36-350]$ & 0.877 \\
\hline Lipase (IU/L) [range] & $48.5[4-781]$ & $34.5[10-889]$ & 0.706 \\
\hline HbA1c (NGSP \%) [range] & $6.65[4.9-13.7]$ & $6.20[4.9-10.5]$ & 0.195 \\
\hline
\end{tabular}

$P E /$ pancreatic exocrine insufficiency, $B M /$ body mass index, $P C$ pancreatic carcinoma, $C P$ chronic pancreatitis, $H b$ hemoglobin, $B U N$ blood urea nitrogen, $C r e$ creatinine, $T P$ total protein, $A / b$ albumin, Amy amylase, $H b A 1 c$ hemoglobin A1c, NGSP national glycohemoglobin standardization program, CEA carcinoembryonic antigen, CA19-9 carbohydrate antigen 19-9, MPD major pancreatic duct 


\begin{tabular}{|c|c|c|c|}
\hline & $\begin{array}{l}\text { PEl group } \\
(n=30)\end{array}$ & $\begin{array}{l}\text { non-PEl group } \\
(n=30)\end{array}$ & $P$-value \\
\hline CEA (ng/mL) [range] & $3.2[1.0-44.4]$ & $2.6[0.7-105.8]$ & 0.261 \\
\hline CA19-9 (U/mL) [range] & $119.50[<1-23210]$ & $61.50[<1-197000]$ & 0.446 \\
\hline \multicolumn{4}{|l|}{ imaging findings } \\
\hline pancreatic hypertrophy,n (\%) & $9(30.0)$ & $3(10.0)$ & 0.053 \\
\hline calcification,n (\%) & $4(13.3)$ & $2(6.7)$ & 0.389 \\
\hline pancreatic cyst,n (\%) & $6(20.0)$ & $5(16.7)$ & 0.739 \\
\hline MPD dilatation,n (\%) & $19(63.3)$ & $13(43.3)$ & 0.121 \\
\hline MPD stenosis,n (\%) & $20(66.7)$ & $12(40.0)$ & 0.038 \\
\hline normal pancreas,n (\%) & $0(0.0)$ & $5(16.7)$ & 0.020 \\
\hline \multicolumn{4}{|c|}{$\begin{array}{l}P E / \text { pancreatic exocrine insufficiency, } B M / \text { body mass index, } P C \text { pancreatic carcinoma, } C P \text { chronic } \\
\text { pancreatitis, } H b \text { hemoglobin, } B U N \text { blood urea nitrogen, Cre creatinine, } T P \text { total protein, } A / b \text { albumin, } \\
A m y \text { amylase, } H b A 1 c \text { hemoglobin } A 1 c, N G S P \text { national glycohemoglobin standardization program, } \\
C E A \text { carcinoembryonic antigen, } C A 19-9 \text { carbohydrate antigen } 19-9, M P D \text { major pancreatic duct }\end{array}$} \\
\hline
\end{tabular}

Expired gas analysis

There was a strong positive correlation between FBHC and FBCC $(r=0.754, P<0.001)$ and a negative correlation between FBHC and FBMC $(r=-0.387, P=0.001)$ (Figs. $1 a$ and $1 b)$. FBHC was significantly higher in the PEl group than in the non-PEl group (median: 2.80 (0.7-28.2) vs. 15.70 (1.4-77.0) ppm, $P<$ 0.001 ) (Fig. 2). Similarly, FBCC was significantly higher in the PEl group $(P=0.001)$, whereas there was no significant difference in FBMC $(P=0.216)$ (Table 2$)$. FBHC had a negative correlation with PABA excretion rate $(r=-0.523, P<0.001)$ and no correlation with the CPR value $(r=-0.067, P=0.608)$ (Figs. 3a and 3b). FBCC showed similar respective correlations $(r=-0.462, P<0.001 ; r=-0.091 P=0.487)$ since it was positively correlated with FBHC. FBMC was not correlated with the PABA excretion rate $(r=0.131, P=$ 0.320 ) or CPR value ( $r=0.081, P=0.541)$. An ROC curve for FBHC and PABA excretion rate was used to determine a cut-off value for FBHC (Fig. 4). A cut-off of 10.7 ppm (AUCROC: $0.796,95 \%$ confidence interval: $0.678-0.913, P<0.001)$ gave a sensitivity of $73.3 \%$ and a specificity of $83.3 \%$ for diagnosis of PEI. 
Table 2

Comparison of expired gas in PEl and non-PEl groups

\begin{tabular}{|llll|}
\hline & $\begin{array}{l}\text { PEI group } \\
(\mathbf{n}=\mathbf{3 0})\end{array}$ & $\begin{array}{l}\text { non-PEl group } \\
(\mathbf{n = 3 0 )}\end{array}$ & $\boldsymbol{P}$-value \\
\hline FBHC (ppm) [range] & $15.70[1.4-77.0]$ & $2.80[0.7-28.2]$ & $<0.001$ \\
\hline FBCC (ppm) [range] & $8.15[0.0-16.5]$ & $4.90[2.6-12.9]$ & 0.001 \\
\hline FBMC (ppm) [range] & $0.55[0.0-36.2]$ & $0.70[0.0-44.9]$ & 0.216 \\
\hline $\begin{array}{l}\text { PEl pancreatic exocrine insufficiency, FBHC fasting breath hydrogen concentration, } F B C C \text { fasting } \\
\text { breath carbon monoxide concentration, FBMC fasting breath methane concentration, } p p m \text { parts per } \\
\text { million }\end{array}$ & & \\
\hline
\end{tabular}

PABA excretion rate-associated changes in intestinal bacterial flora

The bacteria proportions at the 'phylum' level in the PEI and non-PEl groups are shown in Fig. 5a. Bacteroidetes was dominant in both groups. The occupancy by the phylum Firmicutes was higher in the PEl group, and those for Proteobacteria, Verrucomicrobia, and Fusobacteria were lower. At the 'genus' level, the occupancies by the genera Blautia, Faecalibacterium, and Streptococcus were higher and those of Parabacteroides and Akkermansia were low in the PEl group (Fig. 5b). A comparison of microbiomes showed increases in the genera Clostridium, Lachnospira, Veillonella, Selenomonas, and Anaerococcus belonging to the class Clostridia, which are obligate anaerobes, in the PEl group $(p<0.05)$. Increases in the genera Enterococcus and Lactobacillus belonging to the family Lactobacillaceae, and genera Leptotrichia, Prevotella, Serratia, and Aggregatibacter belonging to the family Leptotrichiaceae were also noted (Fig. 5c) $(\mathrm{p}<0.05)$.

\section{Discussion}

Improvement of QOL of patients with pancreatic disease requires detection of $\mathrm{PEl}$ in the early phase, for which a simple diagnostic method for PEl is needed for screening. In humans, hydrogen is only produced in the intestine through degradation and metabolism of unabsorbed food by intestinal bacteria, and about $14 \%$ is excreted via expiration [19]. Based on this information, this study was performed with the hypothesis that simple FBHC measurement may be useful to predict PEI.

The PEl group with high FBHC had a high rate of heavy drinkers, which is consistent with a study that showed that the breath hydrogen concentration is increased by alcohol intake [20]. The significantly lower serum albumin level on blood chemistry and imaging findings of main pancreatic duct stenosis in the PEI group were as previously reported by us, and are considered to result from a negative influence on nutritional status by PEl due to pancreatic duct stenosis [11].

FBHC was significantly higher in the PEI group and had a negative correlation with the PABA excretion rate. Thus, the breath hydrogen concentration increased as exocrine pancreatic secretion decreased. The 
normal limit of FBHC is unclear, but this value varies from 10 to $20 \mathrm{ppm}$ [21]. At present, $\geq 20 \mathrm{ppm}$, the diagnostic criterion for SIBO, is the accepted value $[8,9,21]$, but FBHC $\geq 20$ ppm was found in only 12 of 30 patients in the PEI group (and in none in the non-PEl group). This suggests that $\geq 20 \mathrm{ppm}$ is inappropriate as a screening criterion because it may increase the false negative rate. A cut-off value of FBHC of 10.7 ppm gave favorable sensitivity and specificity for diagnosis of PEl in this study.

Regarding other expired gas, cross-sensitivity of FBCC with the hydrogen concentration has been shown [22] and a strong positive correlation with FBHC was found in the current study. FBHC has been found to decrease in subjects with high FBMC, and these variables had an inverse correlation in this study. Fewer of our subjects produced methane compared with the rate of $44 \%$ in a previous study, and we did not find an association of FBMC with pancreatic function [23].

In comparison of intestinal bacterial flora, as previously reported, increases in the division Firmicutes [24, 25], genus Clostridium [26], and family Lactobacillaceae [27] were observed in PC, CP, and PEI. Of 343 species of intestinal bacteria registered in the Human Microbiome Project, about $71 \%$ encode hydrogenase, an enzyme catalyzing a reversible oxidation-reduction reaction of hydrogen. The division Firmicutes, which significantly increased in the PEI group, accounts for $21 \%$ of the hydrogenase content in bacterial flora in the human colon [28]. The genus Clostridium is a representative hydrogen-producing bacteria producing $1.1-2.3 \mathrm{~mol} \mathrm{H}_{2} / \mathrm{mol}$ glucose at temperatures $\left(30-40^{\circ} \mathrm{C}\right)$ close to that of the human body and has been widely studied in the biomass field $[29,30]$.

The genus Clostridium is one of the main hydrogen sources in the human intestine [31] and is likely to have been the cause of elevation of FBHC in the PEl group. In addition, some of Clostridium spp. form a carbohydrate-associated enzyme complex (a "cellulosome") and 57 cellulosome genes encoding lipase, peptidase, and proteinase inhibitors, in addition to carbohydrate-activating enzymes, have been discovered [32]. Since undigested food flows in the intestine due to PEl, Clostridium with these characteristics may have increased and resulted in an increase in hydrogen. The genus Lactobacillus of the family Lactobacillaceae also produces hydrogen in a medium temperature environment [33], and a state with reduced exocrine secretion (i.e., an intestinal condition with undigested food) may be an advantageous environment for a hydrogen-producing anaerobe.

PERT has been shown to improve undernutrition, gastrointestinal symptoms, and QOL by decreasing undigested food [4]. This suggests that an increase in undigested food is reflected as FBHC elevation, suggesting its potential as an effective pre-test marker before use of PERT. A bag is the only running cost required for breath hydrogen measurement, which reduces the cost. The test time is about 1 minute and the measurement time is about 4 minutes, which are shorter than those in other tests, and the test is noninvasive and can be performed repeatedly. Thus, it may also be useful for judgment of the effect of PERT, as well as for screening prior to treatment.

There are several limitations in this study. First, all subjects were inpatients with diseases, and no samples were obtained from healthy persons. Second, several diseases that may influence the FBHC test 
results were excluded. Third, there were only a few patients with FBMC elevation and the clinical significance of this effect could not be analyzed. Production of methane consumes hydrogen and this may latently influence hydrogen measurement [23]. Resolution of these problems will require accumulation of samples, including from healthy subjects. Within these limitations, we conclude that an increase in undigested food due to PEl increases hydrogen-producing bacteria in human intestinal bacterial flora. This elevates FBHC, which can be measured easily and non-invasively as a reflection of intestinal bacterial flora and as a simple diagnostic method for $\mathrm{PEI}$.

\section{Conclusion}

In patients with $\mathrm{PEI}$, there was an increase in $\mathrm{FBHC}$ levels, which was not examined in previous reports. We believe that FBHC measurement without glucose or lactose loading is useful as a simple method to diagnose PEl. These results suggest that the increased amount of undigested food entering the intestine due to PEI may lead to increased production of hydrogen by genus Clostridium.

\section{Abbreviations}

PEl pancreatic exocrine insufficiency; FBHC fasting breath hydrogen concentration; Cl confidence interval; QOL quality of life; PERT Pancreatic enzyme replacement therapy; PC pancreatic carcinoma; CP chronic pancreatitis; BHT breath hydrogen test; SIBO small intestinal bacterial overgrowth syndrome; CPR the 24hour urinary $\mathrm{C}$ peptide excretion test; $\mathrm{BMI}$ body mass index; MPD main pancreatic duct; ERCP endoscopic retrograde cholangiopancreatography; MRCP magnetic resonance cholangio pancreatgraphy; EUS endoscopic ultrasound; CT computed tomography; FBCC fasting breath carbon monoxide concentration; FBMC fasting breath methane concentration; ROC receiver operating characteristic.

\section{Declarations}

\section{Ethics}

This study was performed after approval by the Ethics Review Committee of Nagoya University Hospital and with written consent from the subjects after they received an explanation of the study (UMIN000020269هUMIN000020777). The study followed the ethics criteria established in the Declaration of Helsinki and subsequent revisions. All study participants provided informed written consent prior to be enrolled in this study.

Consent for publication

Not Applicable.

Availability of data and material

The data of this study are available from the corresponding author upon reasonable request. 
Competing interests

The authors declare that they have no competing interests.

Funding

No funding was obtained for this study.

Contributions

Study concept and design: KU, KY, HK, TH, MN, MI, OE, TI(P.h.D), TI. Analysis and interpretation of the data: YK, KU, HK. Drafting of the article: KU, KM, HK, MF.

Final approval of the article: all authors.

\section{Acknowledgments}

We thank Ms. Akina Ooishi of the Department of Gastroenterology and Hepatology, Nagoya University Graduate School of Medicine for technical assistance in DNA isolation and 16S rRNA gene sequencing.

\section{References}

1. Lindkvist B. Diagnosis and treatment of pancreatic exocrine insufficiency. World J Gastroenterol. 2013;19:7258-66.

2. Capurso G, Traini M, Piciucchi M, et al. Exocrine pancreatic insufficiency: prevalence, diagnosis, and management. Clin Exp Gastroenterol. 2019;12:129-39.

3. Bartel MJ, Asbun H, Stauffer J, et al. Pancreatic exocrine insufficiency in pancreatic cancer: a review of the literature. Dig Liver Dis. 2015;47:1013-20.

4. de la Iglesia-García D, Huang W, Szatmary P, et al. Efficacy of pancreatic enzyme replacement therapy in chronic pancreatitis: systematic review and meta-analysis. Gut. 2017;66:1354-5.

5. Carnie LE, Lamarca A, McNamara MG, et al. The assessment of pancreatic exocrine function in patients with inoperable pancreatic cancer: in need of a new gold-standard. Pancreatology. 2020;20:668-75.

6. Lee AA, Baker JR, Wamsteker EJ, et al. Small intestinal bacterial overgrowth is common in chronic pancreatitis and associates with diabetes, chronic pancreatitis severity, low zinc levels, and opiate use. Am J Gastroenterol. 2019;114:1163-71.

7. Ní Chonchubhair HM, Bashir Y, Dobson M, et al. The prevalence of small intestinal bacterial overgrowth in non-surgical patients with chronic pancreatitis and pancreatic exocrine insufficiency (PEI). Pancreatology. 2018;18:379-85.

8. Ali R, Michelle B, Anthony L, et al. Hydrogen and methane-based breath testing in gastrointestinal disorders: The North American Consensus. Am J Gastroenterol. 2017;112:775-84. 
9. Gasbarrini A, Corazza GR, Gasbarrini G, et al. Methodology and indications of H2-breath testing in gastrointestinal diseases: The Rome Consensus Conference. Aliment Pharmacol Ther. 2009;29(Suppl) 1:1-14.

10. Avallone EV, De Carolis A, Loizos P, et al. Hydrogen breath test: diet and basal H2 excretion: a technical note. Digestion. 2010;82:39-41.

11. Sakai D, Hirooka $Y$, Kawashima $H$, et al. Increase in breath hydrogen concentration was correlated with the main pancreatic duct stenosis. J Breath Res. 2018;12:036004. doi:10.1088/17527163/aaaf77.

12. Schneider AJ, Lohr M, Singer MV. The M-ANNHEIM classification of chronic pancreatitis: introduction of a unifying classification system based on a review of previous classifications of the disease. $J$ Gastroenterol. 2007;42:101-19.

13. Hayashi $D$, Hirooka $Y$, Kawashima $H$, et al. Functional Correlation between the pancreas and the small intestine in humans. Pancreas. 2018;47:601-8.

14. Yamato C, Kinoshita K. A simple assay for measurement of urinary p-aminobenzoic acid in the oral pancreatic function test. Anal Biochem. 1979;98:13-7.

15. Chamberlain JJ, Rhinehart AS, Shaefer CF, et al. A diagnosis and management of diabetes: synopsis of the 2016 American Diabetes Association Standards of Medical Care in Diabetes. Ann Intern Med. 2016;164:542-52.

16. Expert panel on. detection, evaluation treatment of high blood cholesterol in adults. Executive summary of the Third Report of The National Cholesterol Education Program (NCEP) Expert Panel on Detection, Evaluation, And Treatment of High Blood Cholesterol In Adults (Adult Treatment Panel III). JAMA. 2001;285:2486-97.

17. Ito $\mathrm{T}$, Ishiguro $\mathrm{H}, \mathrm{Ohara} \mathrm{H}$, et al. Evidence-based clinical practice guidelines for chronic pancreatitis 2015. J Gastroenterol. 2016;51:85-92.

18. Haaga JA, Alfidi RJ, Zelch MG, et al. Computed tomography of the pancreas. Radiology. 1976;120:589-95.

19. Levitt MD. Production and excretion of hydrogen gas in man. N Engl J Med. 1969;281:122-7.

20. Bode C, Kolepke R, Schäfer K, et al. Breath hydrogen excretion in patients with alcoholic liver disease: evidence of small intestinal bacterial overgrowth. Z Gastroenterol. 1993;31:3-7.

21. Signoretti M, Stigliano S, Valente R, et al. Small intestinal bacterial overgrowth in patients with chronic pancreatitis. J Clin Gastroenterol. 2014;48(Suppl)1):52-5.

22. Costello BP, Ewen RJ, Ratcliffe NM. A sensor system for monitoring the simple gases hydrogen, carbon monoxide, hydrogen sulfide, ammonia and ethanol in exhaled breath. $J$ Breath Res. 2008;2:037011. doi:10.1088/1752-7155/2/3/037011.

23. Bjørneklett A, Jenssen E. Relationships between hydrogen $(\mathrm{H} 2)$ and methane $(\mathrm{CH} 4)$ production in man. Scand J Gastroenterol. 1982;17:985-92. 
24. Jandhyala SM, Madhulika A, Deepika G, et al. Altered intestinal microbiota in patients with chronic pancreatitis: implications in diabetes and metabolic abnormalities. Sci Rep. 2017;7:43640. doi:10.1038/srep43640.

25. Ren Z, Jiang J, Xie H, et al. Gut microbial profile analysis by MiSeq sequencing of pancreatic carcinoma patients in China. Oncotarget. 2017;8:95176-5191.

26. Hamada S, Masamune A, Nabeshima T, et al. Differences in gut microbiota profiles between autoimmune pancreatitis and chronic pancreatitis. Tohoku J Exp Med. 2018;244:113-7.

27. Isaiah A, Parambeth JC, Steiner JM, et al. The fecal microbiome of dogs with exocrine pancreatic insufficiency. Anaerobe. 2017;45:50-8.

28. Wolf PG, Biswas A, Morales $\mathrm{SE}$, et al. $\mathrm{H} 2$ metabolism is widespread and diverse among human colonic microbes. Gut Microbes. 2016;7:235-45.

29. Evvyernie D, Morimoto K, Karita S, et al. Conversion of chitinous wastes to hydrogen gas by Clostridium paraputrificum M-21. Int J Hydrogen Energy. 2001;91:339-43.

30. Hendrickx M, De Vos P, De Ley J. Fermentation characteristics of clostridium pasteurianum LMG3285 grown on glucose and mannitol. J Appl Bacteriol. 1991;70:52-8.

31. Suzuki A, Ito M, Hamaguchi $T$, et al. Quantification of hydrogen production by intestinal bacteria that are specifically dysregulated in Parkinson's disease. PLoS One. 2018;13:e0208313. doi:10.1371/journal.pone.0208313.

32. Tamaru Y, Miyake H, Kuroda K, et al. Comparative genomics of the mesophilic cellulosome-producing Clostridium cellulovorans and its application to biofuel production via consolidated bioprocessing. Environ Technol. 2010;31:889-903.

33. Kim DH, Han SK, Kim SH, et al. Effect of gas sparging on continuous fermentative hydrogen production. Int J Hydrogen Energy. 2006;3:2158-69.

\section{Figures}
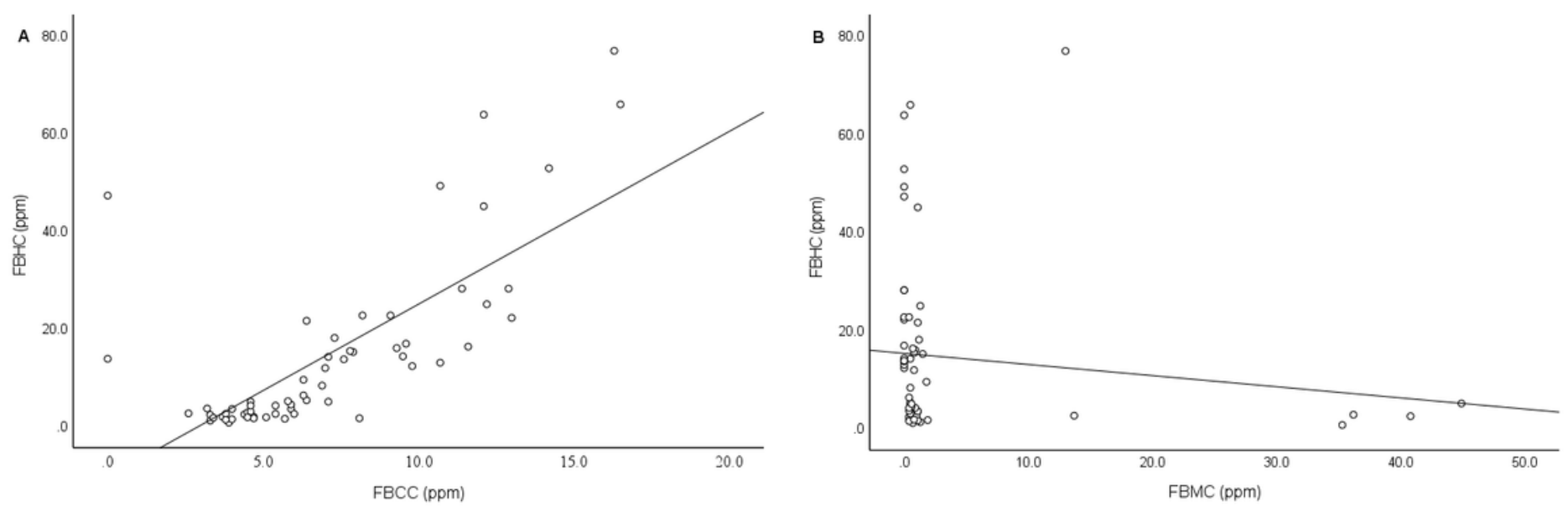

Figure 1 
Correlation of fasting breath hydrogen concentration (FBHC) with fasting breath carbon monoxide concentration (FBCC) and fasting breath methane concentration (FBMC). a: Fasting breath hydrogen concentration (FBHC) and fasting breath carbon monoxide concentration (FBCC). There was a strong positive correlation between FBHC and FBCC $(r=0.754, P<0.001)$. b: Fasting breath hydrogen concentration (FBHC) and fasting breath methane concentration (FBMC). There was a negative correlation between FBHC and FBMC $(r=-0.387, \mathrm{P}=0.001)$

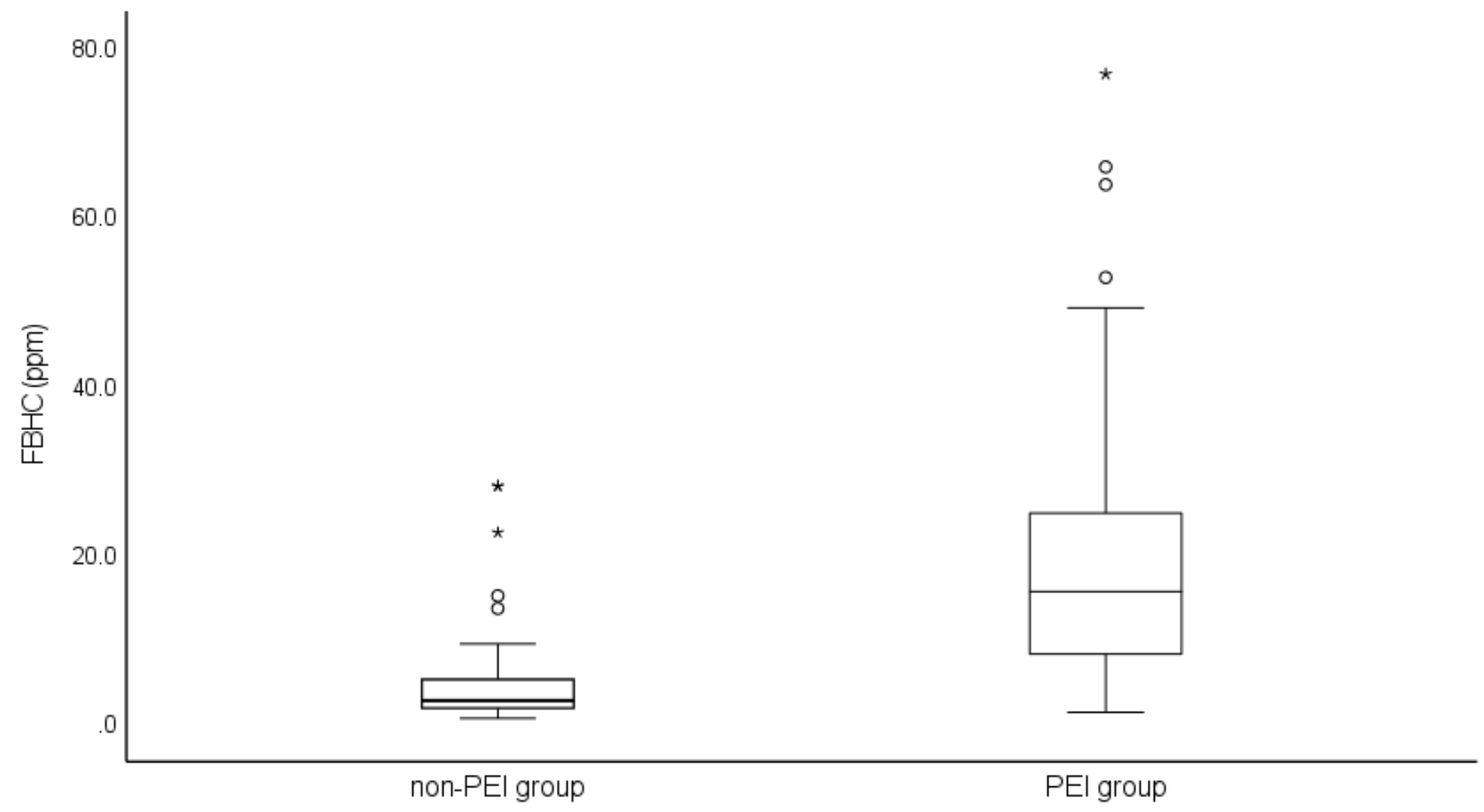

Figure 2

Box plot of fasting breath hydrogen concentration (FBHC) in the exocrine pancreatic secretion test. Box plot of fasting breath hydrogen concentration (FBHC) in non-pancreatic exocrine insufficiency (non-PEI) and PEl groups. The median FBHC of non-PEI and PEl groups were $2.80 \mathrm{ppm}$ and $15.70 \mathrm{ppm}$, respectively $(P<0.001)$ 

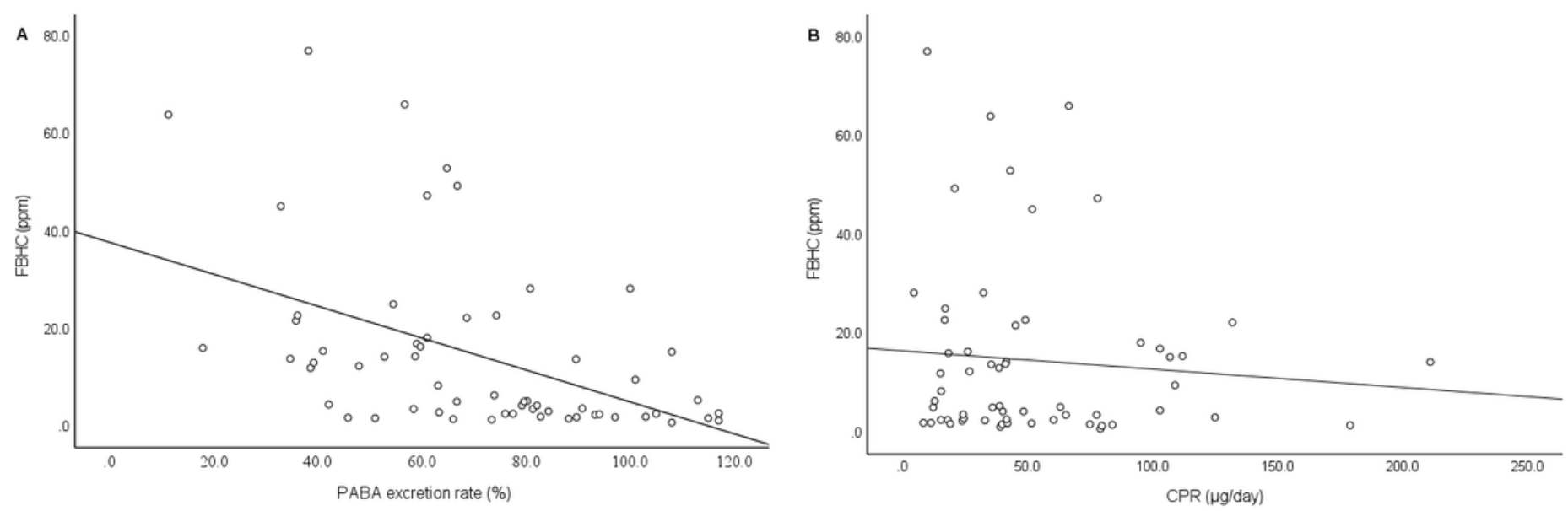

Figure 3

Correlation between breath hydrogen concentration (FBHC) and pancreatic function. a: The result of BTPABA test. FBHC had a negative correlation with PABA excretion rate $(r=-0.523, P<0.001)$. b: The result of 24 urinary $C$ peptide excretion (CPR) test. There was no significant correlation between $\mathrm{FBHC}$ and $\mathrm{CPR}(\mathrm{r}=$ $-0.067, P=0.608)$

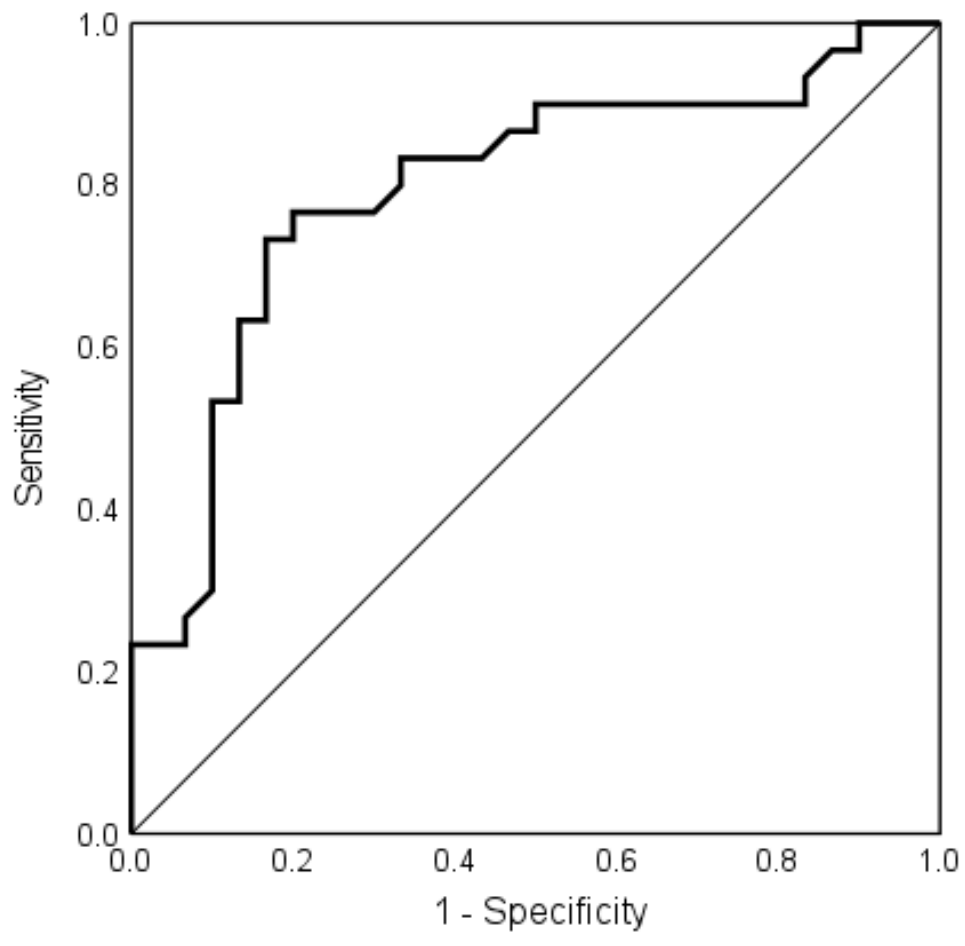

Figure 4

Diagnostic accuracy of pancreatic exocrine insufficiency (PEI) due to elevated fasting breath hydrogen concentration (FBHC) levels. An receiver operator characteristic $(\mathrm{ROC})$ curve for fasting breath hydrogen 
concentration (FBHC) and PABA excretion rate. The cut-off value for the highest sensitivity with maintaining specificity was 10.7 ppm for diagnosis of PEI (the area under ROC (AUCROC): 0.796, 95\% confidence interval: $0.678-0.913, \mathrm{P}<0.001$ )

A

$$
\begin{aligned}
& \text { PEI } \\
& \text { group }
\end{aligned}
$$

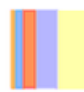

Non-PEI group
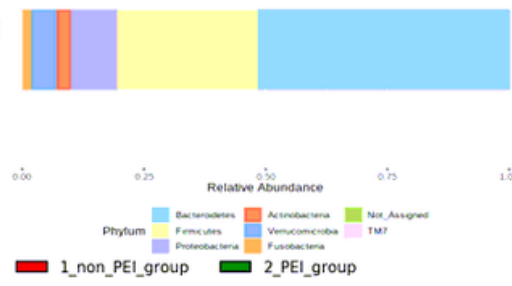

C

$$
\text { 1_non_PEI_group 2_PEI_group }
$$

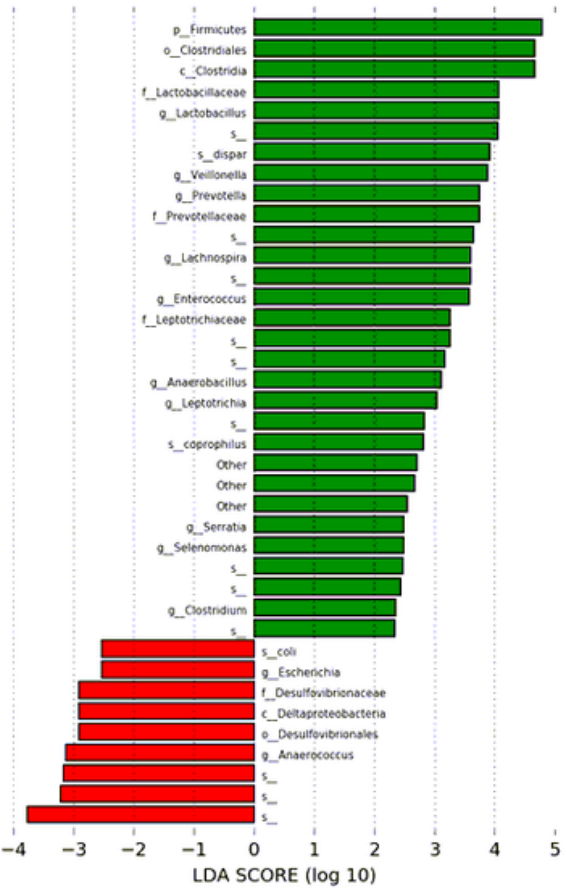

B
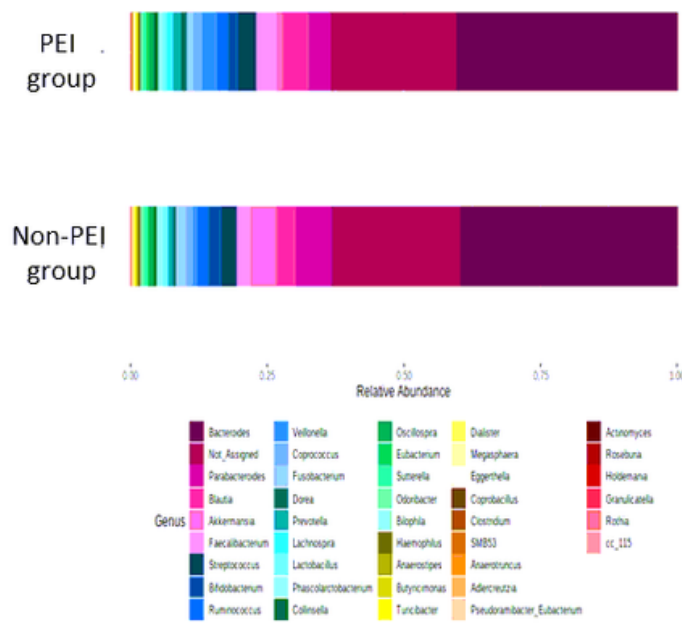

1_non_PEI_group
2_PEI_group

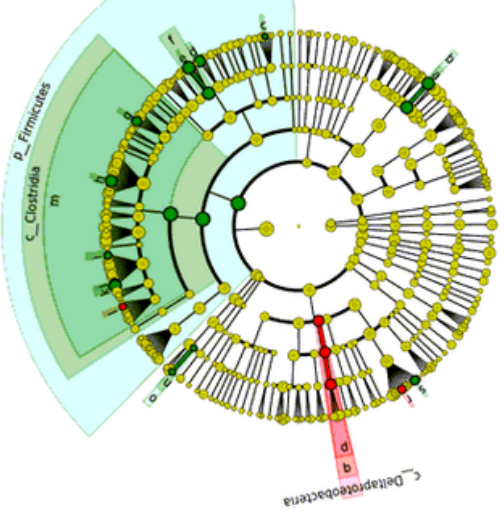
ש a: 9_Prevotella c: 9_Anserobacillus d: 9._Enterococcus E: f_Lactobacillar 9: 9_clostridium 口i: other : is_Setenomonas : g_Vellionella 最: Anserococcus n: 9_Leptotrichia 0:t_Leptotichiacese p:t_Desultoniononacese r: 2 Escherichia 2:0_eschench

\section{Figure 5}

The composition and comparison of bacteria in non-PEI and PEI groups. Stacked bar chart comparing microbiome at the phylum level (a) and genus level (b) in the non-PEI and PEI groups. 